\title{
Repositioning Your EMBA Program And Reinventing Your Brand: A Case Study Analysis
}

Francis Petit, Ed.D., Fordham University, USA

\begin{abstract}
The purpose of this research is to illustrate how Fordham University, the Jesuit University of New York, repositioned its Executive MBA Program and reinvented its brand, over a ten year period. More specifically, this research will analyze the current state of the Executive MBA market and will discuss the best practices and frameworks implemented during this repositioning process, as supported by the research.
\end{abstract}

Keywords: Executive MBA, Branding, Reposition / Reinvention, Rankings, Academic Processes

\section{INTRODUCTION}

1 n March of 1998, Fordham University launched the Transnational MBA, which was positioned as Fordham's Executive MBA. This program, which was transnational and global in scope, was a 60 credit MBA in "Management Systems". In addition, this program operated exclusively out of a conference center in Westchester County, just 20 miles north of Fordham's Lincoln Center Campus in Manhattan. The program met just one weekend per month (Fri-Sun) for 27 months. As a result of this program being offered exclusively out of a conference center, incorporated in its tuition pricing structure were overnight accommodations for two evenings per each weekend plus "executive-style" meals offered by the facility. In addition, this program incorporated, within its curriculum, two to three international residentials to cities such as Dublin, Geneva and Beijing. (Transnational MBA Program, 1998).

This Executive MBA Program was spearheaded and developed by the Dean of the Fordham University Graduate School of Business Administration at that time. This person, who was a 20 plus year veteran of the Executive MBA industry and who was one of the founding members of the Executive MBA Council, the governing body of Executive MBA Programs worldwide, had stated the following during the launch of this program:

I have been involved in the launch of five different executive style MBA programs over the last 15 years, all of which were ranked among the top few nationally and internationally. I can confidently state that the Fordham Transnational MBA offers the best curriculum and delivery format for today's busy professional assuming international business responsibilities. (Transnational MBA Program, 1998).

Overall, this program was considered not only a unique offering in the marketplace but was also developed by a veteran in the field of Executive MBA Programs.

The inaugural class and/or "Cohort \#1" which began their studies in March of 1998 started off with 18 students. Enrollment growth within this period, however, would not be the case, as seen in Table 1.

This lack of consistent and upward enrollment growth, coupled by the fact that this program had a financial breakeven point of 19 students, forced the administration within Fordham University's Graduate School of Business Administration to reevaluate and reassess its Transnational MBA offering. (Sharon Smith, 2002). 
Table 1

Transnational MBA Enrollment - 2000 - 2004

\begin{tabular}{cccc}
\hline Class & Start Date & Graduation Date & Enrollment \\
\hline Cohort \#1 & March 1998 & May 2000 & 18 \\
Cohort \#2 & March 1999 & May 2001 & 14 \\
Cohort \#3 & March 2000 & May 2002 & 14 \\
Cohort \#4 & March 2001 & May 2003 & 23 \\
Cohort \#5 & March 2002 & May 2004 & 13 \\
\hline
\end{tabular}

(Enrollment Statistics, Transnational MBA Program, 2008).

As a result of this reevaluation process, it was decided during the Spring 2002 term that this Executive MBA Program would be repositioned and retooled to not only address the current market needs but to also make it a more attractive program offering in the hopes of generating increased enrollment.

This all led to a newly repositioned Executive MBA Program, which was 22 months in length and launched its first class in August 2003. Below, in Table 2, please find the enrollment trends of this newly repositioned program.

Table 2

Executive MBA Enrollment 2003 - 2008

\begin{tabular}{cccc}
\hline Class & Start Date & Graduation Date & Enrollment \\
\hline Cohort \#1 & August 2003 & May 2005 & 20 \\
Cohort \#2 & August 2004 & May 2006 & 26 \\
Cohort \#3 & August 2005 & May 2007 & 19 \\
Cohort \#4 & August 2006 & May 2008 2009 & 35 \\
Cohort \#5 & August 2007 & May 2010 & 35 \\
Cohort \#6 & August 2008 & & 35 \\
\hline
\end{tabular}

(Enrollment Statistics, Fordham's EMBA Program, 2008).

Overall, this newly repositioned program is operating at capacity as its enrollment is capped at 35 students due to pedagogical concerns by the faculty and space constraints at Fordham University's Lincoln Center Campus. In addition, this program has seen a yearly increase of over five percent with its admissions application received from 2003 through 2008. (Enrollment Statistics, Fordham's EMBA Program, 2008).

As a result of this program momentum and success, Fordham University decided to launch a second EMBA Cohort per year at the University's new satellite campus in West Harrison, New York, starting in 2009. Overall, what seemed to be a program on the brink of collapse, in 2002, has experienced unprecedented growth and success as a result of this repositioning process. This success culminated on September 30, 2008, when the program was ranked as the $25^{\text {th }}$ Top EMBA Program Worldwide by The Wall Street Journal. (Srivastava, WSJ, p. R3).

\section{LITERATURE REVIEW}

\section{The Executive MBA Industry}

This next section will discuss the status of the Executive MBA market. As will be seen by the following statistics and indicators, it is clear that Fordham's Transnational MBA offering operated in a growth stage within the historical context of this market.

For example, the Executive MBA market, even as of 2008, continued to operate in the growth stage of the product lifecycle especially with programs that exist outside the United States. (EMBA Council, 2007). According to the Executive MBA Council, 57\% of programs worldwide are considering either expanding their programs and/or setting up additional satellite locations to penetrate new EMBA markets. (EMBA Council, 2007). In addition, since 1990, there has been a plethora of new programs established. More specifically, since this time period, $84 \%$ of all 
non U.S. programs were established with over a $21 \%$ growth rate in private institutional programs. (EMBA Council, 2003). Furthermore, admission application rates for Executive MBA programs continues to rise as there has been a $25 \%$ increase in applications received with the northeast experiencing a $14 \%$ increase. Such a continued increase over time has not only increased cohort (class) size $8 \%$ to 43 students within schools from the Northeast but has also decreased the acceptance rate from $67 \%$ to $63 \%$. (EMBA Council, 2007).

Mean salaries, in addition, continue to rise for EMBA students and graduates. For example, the mean salary for 2007 EMBA graduates increased $21 \%$ in two years to $\$ 130,056$. (EMBA Council, 2007). Over time, these salary increases are up from $\$ 96,300$ which was the mean salary for EMBA students in 2001. (EMBA Council, 2003).

Furthermore, students appear to be more satisfied than ever with their consumption of the EMBA product. Student exit surveys indicate that $99 \%$ of EMBA students would refer their programs to other prospective students. (EMBA Council, 2005). The research also indicates that 50\% of EMBA graduates report new responsibilities gained as a result of their program entry and about 33\% of these students, during their studies, received a promotion. (EMBA Council, 2005). It also takes only 17 months from starting a program for the sponsoring company to gain its return on investment and almost $80 \%$ of EMBA graduates report that their value to their organizations increased as a result of entering a program in the first place. (EMBA Council, 2005).

All of the above data indicates that Executive MBA students are not only satisfied with the "EMBA Experience" but are more than willing to refer candidates to their programs and have received substantial salary increases and additional responsibilities as a result of program entry.

However, there have been obstacles mounting over time that have been impacting the industry yet a growth market still prevails. For example, there have been drastic reductions in corporate financial sponsorship for these programs. In 2001, 44\% of all EMBA students were fully financially sponsored and only $9 \%$ were self financially sponsored. (EMBA Council, 2003). In 2007, full financial sponsorship dropped to $33 \%$ and self financial sponsorship surged to 33\%. (EMBA Council, 2007). This data indicates that while corporations are increasingly unwilling to pay full tuition amounts for these programs, students remain willing to shoulder the increased financial burden. Such a burden and obstacle, according to Ethan R. Hanabury, Associate Dean for EMBA Programs at Columbia Business School, has created the biggest shift in the EMBA market itself. (Speizer, January 15, 2007).

Further obstacles facing the industry can also be seen with the growing disparity of tuition. For example, there are four private institutions in the New York City area that, in the Fall of 2007 according to their web sites, charged the following full tuition for each respective program: $\$ 133,200, \$ 128,000, \$ 122,400$, and $\$ 77,500$. However, the fifth school, which is a public institution, was only priced, full tuition, at $\$ 63,500$ according to their web site during this time. Such a disparity in tuition is now common by region within the Executive MBA market. (Petit, 2008). While there is no exact formula in pricing EMBA Programs from an institution's perspective, one strategy is that the tuition should not exceed the current mean salary of students enrolled in such programs. (Scalberg, Spring 2001). While the mean salaries of EMBA students are generally high, this strategy dictates that tuition should follow suit.

Even with these increasing mean salaries of students enrolled in such programs, one cannot ignore these mounting industry growth obstacles such as dwindling corporate financial sponsorship and the disparity of tuition prices. Even with these obstacles, the EMBA industry continues to be in the growth stage of the product lifecycle. Such growth has led the EMBA Programs to be the cash cows of not only graduate business schools but also the universities themselves. (Jahera, 2006). Such revenue generation potential has enabled, for example, the University of Western Ontario and Queens University in Canada to generate over \$15 million per year in tuition revenue alone for each respective program. (Canadian Business, November 11, 2002).

Consequently, as can be seen by the research, the EMBA market, even with the presence of some obstacles, continues to experience growth. Fordham's Transnational MBA Program, apparently was operating in a growth market, however, could not, for a variety of reasons that will be explained further within this research, sustain growth and build momentum. 


\section{METHODOLOGY}

During the Spring 2002 semester, administrators within Fordham University's Graduate School of Business Administration embarked on a repositioning initiative for its Executive MBA Program. This repositioning effort was led by the Assistant Dean and Director for Executive Programs working in conjunction with the Dean of the Graduate School of Business Administration.

The first stage of the process included a market research component in which the Assistant Dean interviewed the following program stakeholders on their thoughts and perspectives of the important attributes that constitute an ideal Executive MBA Program (Table 3):

Table 3

Stakeholder Sample

\begin{tabular}{lc}
\hline \multicolumn{1}{c}{ Stakeholder } & Total Interviewed \\
Program Alumni & 20 \\
Faculty & 5 \\
Prospective Students & 10 \\
Current Executives & 10 \\
Human Resource Professionals & 5 \\
Total & 50 \\
\hline
\end{tabular}

Each stakeholder surveyed was selected by either the Assistant Dean and/or volunteered to be interviewed.

The second stage of the repositioning process included the presentation of the research findings by the Assistant Dean to the Chairs of the academic areas within the Graduate School of Business Administration. The areas are as follows:

1. Accounting and Taxation

2. Communications and Media Management

3. Finance and Business Economics

4. Information Systems

5. Legal and Ethical Studies

6. Management Systems

7. Marketing

This stage, which spread over a six month period, included lengthy discussions among the Assistant Dean and Area Chairs on how best to incorporate the findings into a newly repositioned program curriculum. A prototype repositioned curriculum was developed and fine tuned until its final draft was developed.

The third stage required the receipt of the necessary academic approvals from the Curriculum Committee and Joint Council within the Graduate School of Business Administration.

The final stage incorporated the successful launch of the repositioned program and its subsequent strategies for continued growth over time.

\section{RESULTS}

Upon conducting in depth interviews of what constitutes an ideal Executive MBA Program among the 50 stakeholders within the sample set, the following 5 themes emerged as critical attributes of importance:

1. Program Brand

2. Program Format/Time Away from Office

3. Program Price

4. Alumni Network 


\section{Recruitment/Admissions Process}

In terms of the Program Brand, each stakeholder interviewed believed that this attribute was of paramount importance. Eighty percent $(80 \%)$ of the stakeholders interviewed indicated that rankings in publications such as Business Week, U.S. News and World Report, Financial Times and The Wall Street Journal are not only essential but greatly add to the perception of the brand. This group believed that Executive MBA Programs must not only be ranked but each institution must do everything in its power to improve the rankings and in essence enhance its brand. The remaining $20 \%$ of the sample set, which included mostly "Faculty" and "Human Resource Professionals", indicated that school rankings, while important, were not the sole driver of the brand and there are many good Executive MBA Programs that exist that are not highly ranked. However, this group believed that each institution must have a rankings strategy and must play the "rankings game" given the perception and leverage the rankings hold in the market. Overall, it must be noted that the Program Brand emerged as the single most important attribute among the stakeholders interviewed and the rankings have a profound impact on the perception of this brand.

The second attribute, in terms of importance, was Program Format/Time Away from Office. Each of the stakeholders interviewed indicated that Executive MBA students have extremely busy lifestyles. Increased responsibilities at work and at home have added to decreased leisure time available. (Rein, Kotler and Shields, p. 8). Overall, each stakeholder interviewed indicated that a convenient program format that allowed students limited time away from the office but gave them the ability to obtain the MBA in a time efficient manner was highly desirable which was further reinforced within the literature. (Petit, 2008).

The third most important attribute that emerged from this study was Price. Seventy (70\%) percent of the sample interviewed indicated that the tuition price of a program played or should play a major role in the program selection process. This group mainly comprised of "Prospective Students", "Human Resource Professionals" who support such programs, "Current Executives" and "Program Alumni". The dwindling level of corporate financial sponsorship, as indicated earlier, coupled with an unknown economy and increased level of debt among this segment could play a role behind this attribute's importance. Overall, among the sample set, Price did in fact matter.

The fourth attribute, in terms of importance, was the Alumni Network available to Executive MBA students. While career services is becoming an expectation within Executive MBA Programs given the decline in corporate financial sponsorship, such services, in reality, are in its infancy stage among most institutions. The reason supporting this fact is that while Executive MBA students were fully financially funded, institutions did not offer career services options to this segment as it may in fact destroy the relationship between the sponsoring company and institution. Now that companies are not paying full freight for such programs, the career service option is becoming an expectation among students. As a result, Executive MBA Programs, in general, are scrambling to offer a career service option to this population. (Petit, 2008). With this as a background, the Alumni Network available to Executive MBA students is very important. Within the sample set surveyed, $60 \%$ believed that this network availability for current students as well as graduates was of critical importance. The group that strongly favored these views were mostly comprised of "Prospective Students", "Current Alumni" as well as some "Current Executives" in the field. In essence, if a school cannot yet offer an extensive career service option to students, they must at least offer access to the Alumni Network for each program.

The attribute which placed fifth in terms of importance was the Recruitment/Admissions Process for such programs. Within the sample set, 50\% indicated that this attribute has and should play a critical role in program selection. Since Executive MBA Programs are considered "luxury products" with a premium pricing strategy, it may be the case that prospective students expect to be "dazzled" during this process. Interestingly, some of the comments from "Program Alumni", "Human Resource Professionals" and "Current Executives" were that various schools "came after them hard" and were "relentless". These institutions certainly made these prospective students "feel wanted". Overall, the method and extent a prospective student is or was courted by an institution does make a difference among the sample set. 
What is interesting to note is the Program Faculty and Curriculum, did not place as critical attributes of importance among the stakeholders in the sample set. This contradicts the notion that the Program Faculty and Curriculum are the "heart and soul" of top Executive Programs. (Petit, 2005). Perhaps, within this "Experience Economy", outstanding faculty and an innovative curriculum are now an understood and expected feature and benefit of all Executive MBA Programs. Therefore, the curriculum and faculty may not be enough of a differential any longer as students are evaluating the entire "experiential offering" (Petit, 2005).

\section{Factors Supporting The Results}

As indicated from what was learned from participating in this repositioning process as well as from the research, below please find program facts that support the findings.

\section{Program Price}

The Transnational MBA Program, for the Class of 2004, was priced for full tuition at $\$ 82,000$. (Transnational MBA Program 1998). The costs for the delivery of the Transnational MBA Program were high given that this program operated entirely out of a conference Center. (Smith, 2002). As a result, this program was priced at a $25 \%$ higher rate than two competing regional institutions. (EMBA Council, 2003). With full corporate financial sponsorship dropping from $41 \%$ industry wide in 2001 to $33 \%$ in 2007 and with self sponsored students increasing from $9 \%$ in 2001 to $33 \%$ in 2007 , there is strong reason to believe that given the market conditions, executive students could have become more price sensitive for Fordham's program. (EMBA Council, 2007). Such potential price sensitivity, from a pricing psychology perspective, may have been a result of the "Expenditure Effect" and the "Substitute Effect" as increased expenses among current and prospective students plus more available lower priced alternatives may have played a factor in the lack of enrollment growth. (Nagle and Holden, pp. 73-102).

\section{Program Length}

Per the research conducted by the Executive MBA Council, the average length per EMBA Programs in the marketplace is twenty one months. (EMBA Council, 2007). With the Transnational MBA being 27 months in length, it exceeded the industry average length for programs thus potentially making it more unattractive to prospective students. Completing the degree in a time efficient manner, as determined by this study, was important and the Transnational MBA Program did not fully satisfy this demand.

\section{Time Away from Office}

A recent study conducted on the important attributes for prospective students during the Executive MBA search and selection process ranks "institutional brand" and "program format" as the top two attributes of importance. (Petit, 2008). Time required away from the office to attend a program was found to be an integral part within the "program format" attribute. In essence, this study found that executive students did not or could not miss extensive periods of work to attend a program. (Petit, 2008). The Transnational MBA Program, with two to three required international residentials, forced students to miss an additional week of work per residential along with the one Friday per month. Such a program schedule which required blocks of time away from the office conflicts with previous research as well as the current findings that time away from the office does matter.

\section{Sales Process}

The recruitment and sales process to generate enrollment for an Executive MBA cohort is considered very labor intensive given it is a premium priced product. (Petit, 2005). Executive MBA students not only pay a premium tuition rate and seek financial sponsorship from their organizations but must also obtain approval to miss work to attend the required class sessions and residencies. In addition, since student are paying more out of pocket for these programs, they are also demanding a high impact academic and non-academic experience. (Petit, 2005). Consequently, to deliver on this challenge, programs should incorporate additional resources, in terms of personnel and program support. While the Transnational MBA Program had a Director in place reporting to the Associate 
Dean for Corporate Programs, there was no additional secretarial and/or professional personnel, besides transcient graduate assistants, to assist with the sales and program delivery. In addition, recruitment and sales, which must be a twelve month per year focus, was not the case. Consequently, during the existence of the Transnational MBA, it was discovered, during the repositioning process, that selling the program was not a top priority in terms of time and resources allocated to this task. As this research found, students are being heavily recruited by other schools. Perhaps prospective students were not as strongly courted for Fordham's Transnational MBA Program.

\section{Lack of Innovative Mindset}

In order to achieve true innovation within an organization, there must be an innovative mindset cascaded throughout the culture of an institution. Innovation is not process oriented or procedural, rather it is a state of being. (Kuczmarski, 2005). CEO's and other institutional leaders (i.e. Deans and Provost's etc.) are hesitant to engage an organization within an innovation initiative given not only the risks associated with it but also innovation takes time, more so than quarterly earning reports and fiscal year revenues that beckon. (Kuczmarski, 2005).

With this as a backdrop, one must ask if there existed a true innovative mindset within the institution in order to support the development and growth of the Transnational MBA Program? For example, were there enough resources and time given to the program in order for it to grow and be successful or did the institution change its direction too soon given that enrollment and financial goals were not met? Was the new leadership for the Graduate School of Business Administration more apt to cutting this program since it was developed under a previous administration? Was the institution ready, from a strategic perspective, to operate an entire program out of a conference center when available classroom space existed on campus? Lastly, was the University ready, from a procedural perspective, to customize billing services, as required by these type of programs, as opposed to centralizing these functions throughout the organization. Innovation is, once again, a mindset where "outside the box" thinking is not only encouraged but also required. (Kuczmarski, 2005). Perhaps the institution, like so many institutions, was not truly innovative in its support for the Transnational MBA Program.

\section{IMPLEMENTATION OF THE FINDINGS}

The 5 themes that emerged from the research as critical attributes of importance of what constitutes an ideal Executive MBA Program were incorporated within the repositioning process in the following manner:

\section{Program Brand}

It was decided that in order to differentiate the product within the marketplace, the entire Executive MBA Experience would have to be taken into consideration. It was also decided that the features and benefits of any product, including an Executive MBA Program (i.e. academic curriculum and faculty), are a given and that consumers (students) are searching for more than just the standard features and benefits. (Schmitt, 2003). With that said, an elaborate non-academic component was added to the Fordham Executive MBA Experience. This component included a comprehensive wine tasting seminar with the premise that in order to set the right tone for a business meal, one must know what wines go with what foods. It is an acquired skill. Similarly, a golf clinic was also added to the program with the premise that business relationships are not only nurtured on the golf course but golf, like business, require the same skill set in terms of strategy and risk taking. In addition, a management and jazz simulation was also incorporated within the program as a result of a partnership developed with Jazz at Lincoln Center. Furthermore, yoga and meditation have been introduced as a relaxation technique for pressured executives. Overall, the goal has been to build the Fordham Executive MBA Brand with not only a high impact academic program, which is now assumed within the "Experience Economy", but also a high impact non-academic experience with the ultimate goal of creating true product evangelists among the student body.

\section{Program Format/Time Away from Office}

It was decided to keep the one weekend per month format (Friday - Sunday, 9:00 am - 5:00 pm) since this format would be unique among all local competitors. It was also decided to require one international residential (as opposed to two to three) as a capstone pedagogical experience. This would allow the program to not only end in a 
crescendo but it would also allow the executive students to spend less time away from the office which emerged as an important attribute within the research.

\section{Program Price}

It was decided to move the program entirely out of the conference center and back to campus. Instead of each weekend offered exclusively out of the conference center only three weekends are offered at this facility. Such a move allowed the institution to greatly decrease its operating costs. As a result, tuition for the program was decreased by $25 \%$. The goal of this strategy was to make this tuition price more attractive to the partially sponsored and self sponsored candidate.

\section{Alumni Network}

An alumni directory, for Fordham's Executive MBA Program, was created for the exclusive use of current Executive MBA students and graduates. In addition, the goal of this directory is to be utilized by also program administration as a tool to develop sponsored events and also for ranking publication surveys.

\section{Recruitment/Admissions Process}

Recruitment for this program has transformed itself into a twelve month per year initiative. Information sessions are now scheduled for each month of the calendar. The Assistant Dean for the program spends an increased percentage of his time recruiting and selling the program. Also, two full time positions with the title of Program Associate have been added within this Department. One of the Program Associates devotes $50 \%$ of her time to recruiting prospective students. As such, additional resources in terms of time and money have been allocated to sell this program.

\section{CONCLUSION}

This research illustrates the process that Fordham University, the Jesuit University of New York City, underwent when it repositioned its Executive MBA Program in 2002. The success of this repositioning effort culminated on September 30, 2008, when The Wall Street Journal ranked the Fordham University Executive MBA Program as the $25^{\text {th }}$ Top Ranked EMBA Program Worldwide. The Program was also Ranked $20^{\text {th }}$ by The Wall Street Journal on December 10, 2008 for its Return on Investment. The research illustrates not only the important EMBA attributes from the stakeholders surveyed but also how Fordham University operationalized these findings into a newly repositioned program.

\section{AUTHOR INFORMATION}

Francis Petit is the Assistant Dean and Director of Executive Programs at Fordham University Graduate School of Business Administration. In his overall work with executive students, Dr. Petit has established executive programs in North America, South America, Europe, Asia and the Middle East. He holds a Doctorate in Economics and Education from Columbia University and serves as an Adjunct Associate Professor of Marketing at Fordham University.

\section{BIBLIOGRAPHY}

1. “A Lesson in Business,” (November 11, 2002), Canadian Business, Toronto, Vol. 75.

2. Enrollment Statistics, (2008), The Transnational MBA Program.

3. Enrollment Statistics, (2008), Fordham's Executive MBA Program.

4. "Executive MBA Industry Trends and 2003 Research Results", (2003), The Executive MBA Council.

5. Jahera, John S. (2006), "Education for the Educated: An Administrative Perspective," Journal of Executive Education, Vol. 5, Issue 1.

6. Kuczmarksi, Thomas D. (2005), Innovation: Leadership Strategies for the Competitive Advantage, Book Ends Publishing, Chicago, Illinois, pp. 1-21. 
7. Nagle, Thomas T. and Holden, Reed K. (2002), The Strategy and Tactics of Pricing: A Guide to Profitable Decision Making (Third Edition), Prentice Hall, Upper Saddle River, New Jersey, pp. 84-102.

8. Petit, Francis (2005), "Incorporating Customer Experience Management Concepts within your Executive MBA Program,” Journal of Executive Education. Kennesaw State University, p. 65 - 78.

9. Petit, Francis (Forthcoming, 2008), “An Exploratory Analysis of The Impact of Price on the Search and Selection Process for Executive MBA Programs," Journal of Executive Education, Kennesaw State University.

10. Rein, Irving, Kotler, Phililp, and Shields, Ben. (2006), The Elusive Fan: Reinventing Sports in a Crowded Marketplace, McGraw-Hill, p. 1 -8.

11. Scalberg, Enerst J. (Spring 2001), "Lessons from China", Selections, Santa Monica, Vol. 1, Issue 1, pp. 6-10.

12. Schmitt, Bernd. (2003), Customer Experience Management: A Revolutionary Approach to Connecting with your Customers, John Wiley \& Sons, Inc., New Jersey

13. Smith, Sharon. (Spring 2002). TMBA Program Analysis Meeting.

14. Speizer, Irwin. (January 15, 2007), "Back to School: Executive Programs See Resurgence," Workforce Management, Costa Mesa. Vol. 86, Issue 1, pp. 19-22.

15. Srivastava, Samar. (September 30, 2008), “And the Best Executive M.B.A. Programs Are...," The Wall Street Journal, Dow Jones \& Company, New York, page R3.

16. "The Impact of Executive MBA Education", The Executive MBA Council, 2005.

17. Transnational MBA Program, (1998), Fordham University, Graduate School of Business Administration, $\mathrm{p}$ 1-4.

18. 2007 Executive MBA Survey Results, (2007), Executive MBA Council. 
NOTES 